\title{
Whose Job Is It Anyway? Swedish General Practitioners' Perception of Their Responsi- bility for the Patient's Drug List
}

\author{
Pia Bastbolm Rabmner, $\mathrm{PhD}^{1,2,3}$ \\ Lars L. Gustafsson, $M D, P b D^{1,4}$ \\ Inger Holmström, RN, $\mathrm{PbD}^{3}$ \\ Urban Rosenquist, $M D, P b D^{3}$ \\ Göran Tomson, $M D, P b D^{2,5}$ \\ 'Department of Drug Management and \\ Informatics, Stockholm County Council, \\ Sweden \\ ${ }^{2}$ Medical Management Centre, Department \\ of Learning, Informatics, Management, and \\ Ethics, Karolinska Institutet, Stockholm, \\ Sweden \\ ${ }^{3}$ Department of Public Health and Caring \\ Sciences, Health Service Research, Uppsala \\ Science Park, Uppsala, Sweden \\ ${ }^{4}$ Division of Clinical Pharmacology, Depart- \\ ment of Laboratory Medicine, Karolinska \\ Institutet, Karolinska University Hospital \\ Huddinge, Sweden \\ ${ }^{5}$ Department of Public Health Sciences, \\ Division of International Health (IHCAR), \\ Karolinska Institutet, Stockholm, Sweden
}

Conflicts of interest: none

\section{CORRESPONDING AUTHOR}

Pia Bastholm Rahmner, PhD

Department of Drug Management and Informatics

Stockholm County Council

Box 175 33, SE-118 91

Stockholm, Sweden

pia.bastholm@sll.se

\begin{abstract}
PURPOSE Information about the patient's current drug list is a prerequisite for safe drug prescribing. The aim of this study was to explore general practitioners' (GPs) understandings of who is responsible for the patient's drug list so that drugs prescribed by different physicians do not interact negatively or even cause harm. The study also sought to clarify how this responsibility was managed.
\end{abstract}

METHODS We conducted a descriptive qualitative study among 20 Swedish physicians. We recruited the informants purposively and captured their view on responsibility by semistructured interviews. Data were analyzed using a phenomenographic approach.

RESULTS We found variation in understandings about who is responsible for the patient's drug list and, in particular, how the GPs use different strategies to manage this responsibility. Five categories emerged: (1) imposed responsibility, (2) responsible for own prescriptions, (3) responsible for all drugs, (4) different but shared responsibility, and (5) patient responsible for transferring drug information. The relation between categories is illustrated in an outcome space, which displays how the GPs reason in relation to managing drug lists.

CONCLUSIONS The understanding of the GP's responsibility for the patient's drug list varied, which may be a threat to safe patient care. We propose that GPs are made aware of variations in understanding responsibility so that health care quality can be improved.

Ann Fam Med 2010;8:40-46. doi:10.1370/afm.1074

\section{INTRODUCTION}

$\mathrm{D}$ rug therapy is an intervention for most diseases. Although the positive effects of drugs are multiple, drug use also involves the risk of potential drug-related problems, such as drug-drug interactions or side effects. As many as $10 \%$ to $20 \%$ of hospital admissions may be attributed to drug-related problems. ${ }^{1,2}$ Patients are particularly vulnerable to drug errors when transferred between different levels of care, and an estimated $46 \%$ of the errors occur on admission or discharge from hospitals, when new orders are written. ${ }^{3}$

Studies have shown interventions with medication reconciliation to be effective in reducing drug errors in the communication process between physicians. ${ }^{4-6}$ This finding suggests that a database containing all drugs prescribed to a patient may enhance safety. A new law passed in Sweden on July 1,2008 , allows for information sharing between databases. ${ }^{7}$ Challenges include adding nonelectronic medical records to databases, as well as getting the different computer programs to communicate.

Swedish general practitioners (GPs) do not have a gatekeeper function, and the patients are generally allowed to seek care from specialists without a referral. ${ }^{8}$ Increased specialization in health care means patients 
can see several physicians but are mostly followed up in primary care. Medical documentation is thus scattered among settings, which makes it difficult for GPs to get full access to information. ${ }^{9}$ Regarding the responsibility for their patients' prescription drug use, GPs are required to conform to the following regulation of the Swedish National Board of Health and Welfare $^{10}$ :

It is not one single health care professional who is responsible for the current drug list. Each GP is responsible for his/ her prescriptions and that current patient drugs are available on a drug list. GPs should, if possible, inform themselves about other drugs that the patient uses and assess whether the current prescription is appropriate.

The strategies to promote rational and safe drug prescribing are many, but health care professionals have focused almost exclusively on improving the quality of their own prescribing decisions. ${ }^{11}$ Challenging questions are thus raised about how GPs perceive their responsibility for the patient's current drug list when it includes drugs prescribed by different clinicians. To our knowledge this issue has not yet been investigated.

The aim of our study was to explore how Swedish GPs perceive who is responsible for the patient's drug list and how this responsibility is managed.

\section{METHODS}

\section{Research Design}

The study was conducted using a phenomenographic approach. ${ }^{12}$ The main focus of such an investigation is to describe the variations in the ways individuals experience and relate to phenomena. ${ }^{13}$ In phenomenographic research a strategic sample is preferred, because the researchers interest is to capture diversity in a well-structured sample. ${ }^{13}$ Twenty informants are usually sufficient to capture the potential variations in ways of experiencing a phenomenon, ${ }^{14}$ and this sample size supports both the breadth and depth of the variations in the GP's understandings of responsibility. Semistructured interviews form the basis for data collection. The final results, described in an outcome space that shows the hierarchical relationship between so-called categories, is displayed as a figure. This figure is defined in terms of increasing complexity and might be seen as a subset of comprehensive or complex ways of understanding responsibility..$^{13}$ Reflecting on the outcome space has been shown to be a useful educational tool for changed understandings among professionals. ${ }^{14-16}$

The study design was approved by the regional Ethics Committee at Karolinska Institutet in Stockholm, Sweden, Dnr 2007/326-31/3.

\section{Informants and Data Collection}

All physicians interviewed were GPs $(n=17)$ or were in their residency training as a GP $(n=3)$. Informants with differences in background characteristics were purposively selected ${ }^{17}$ from a register provided by the health authorities. A total of 13 different health care centers were represented in the Stockholm area.

The interviews were conducted at the physicians' workplace between January and September 2007. All interviews were made by the first author (P.B.R.). To maintain a focus on the physicians' experience, they were asked to describe and freely reflect on the following questions: "Who is ultimately responsible for the patient's drug list when medications are prescribed by different physicians? Do you take that responsibility, and, if so, how?" Based on the answers, follow-up questions were used to clarify and deepen the informants answer. By asking such question as, "What do you mean?" or "Could you give an example?" we reached information reflecting actual work experiences. In this study, we defined a drug list as the current patient-specific list of drugs prescribed by all health care clinicians

The interviews lasted between 35 and 85 minutes (median 58 minutes), were audio recorded, and were transcribed verbatim. The identities of the informants were removed in the transcripts to guarantee confidentiality.

\section{Data Analysis}

The analysis was carried out by a behavioral scientist (P.B.R.), a medical doctor (G.T.), and a registered nurse (I.H.). The other authors (U.R., L.L.G.) acted as co-readers. The analysis was based on a phenomenographic procedure, ${ }^{13}$ as described in 5 steps:

1. The transcribed text was read repeatedly by the 3 researchers independently to gain an overall impression

2. Parts in the transcripts where the informants responded to the research questions were marked, and a preliminary description of each GP's predominant view was noted. These parts were considered to be the essential content of the data.

3. The descriptions from all interviews were compared and grouped into categories of similarities and differences. No predetermined categories were used. The descriptions were discussed; when opinions differed, such as about their meaning or origin, we returned to the transcripts and sought evidence to establish consensus. This iterative process was used throughout the whole analysis, ie, moving from the whole transcript to the condensed description and back again to determine the physicians' predominant understanding of responsibility of the patient's drug list and its management. When each category was established, it was given a suitable label. Saturation was 
reached after analyzing 18 interviews. Quotations were selected to illustrate the informants' understandings in the categories.

4. Each transcript was reread once more to look for the informants' less-dominant understanding of responsibility. This step was undertaken to ensure that no aspects were overlooked.

5. A structure of the hierarchical relation between categories was created. Focus was on what the GPs talk about in regards to their perceived responsibility for the patients' current drug lists and how they managed

\section{Table 1. Demographic and Employment} Characteristics of Participating Physicians

\begin{tabular}{lc}
\hline Characteristic & No. \\
\hline Female & 7 \\
Male & 13 \\
Age (mean), y & $32-64(51)$ \\
Years in profession, range (mean) & $1-32(8)$ \\
Years as GP, range (mean) & $0-27(14)$ \\
Employment conditions & \\
$\quad$ Private practice & 8 \\
$\quad$ National Health Service & 12 \\
\hline GP = general practitioner. & \\
\hline
\end{tabular}

this responsibility. This constitutes the outcome space describing the internal relation between the categories of description.

\section{RESULTS}

Table 1 displays the demographic and practice characteristics of the 20 participants in the study. We distinguished 5 categories of understanding responsibility that reflect 5 approaches to the issue of managing responsibility. Table 2 displays information about each GP's predominant and less-dominant ways of understanding. A combination of views was found among all 20 GPs (Table 2); it seems that each GP could adopt several approaches depending on the patient and the situation.

\section{Category A. Imposed Responsibility}

The GPs felt an imposed responsibility for unfamiliar drugs that were prescribed by another physician. When patients came to the GPs for follow-up treatment or to renew prescriptions prescribed by other specialists, the GPs were sometimes responsible for signing drug lists for conditions that were beyond their competence to manage, and they had little information about medical indications for or changes to the drug list.

Table 2. General Practitioners' Ways of Understanding Responsibility for Current Patient Drug Lists $(\mathrm{N}=20)$

\begin{tabular}{|c|c|c|c|c|c|c|}
\hline $\begin{array}{l}\text { GP } \\
\text { Identification } \\
\text { No. }\end{array}$ & $\begin{array}{c}\text { Sex of } \\
\text { Interviewee } \\
\text { (Years in } \\
\text { Profession) }\end{array}$ & $\begin{array}{l}\text { Category A } \\
\text { Imposed } \\
\text { Responsibility }\end{array}$ & $\begin{array}{l}\text { Category B } \\
\text { Responsible } \\
\text { for Own } \\
\text { Prescriptions }\end{array}$ & $\begin{array}{c}\text { Category C } \\
\text { Responsible } \\
\text { for All } \\
\text { Drugs }\end{array}$ & $\begin{array}{c}\text { Category D } \\
\text { Different } \\
\text { but Shared } \\
\text { Responsibility }\end{array}$ & $\begin{array}{c}\text { Category E } \\
\text { Patient Transferring } \\
\text { Drug Information }\end{array}$ \\
\hline 2 & Male (24) & ++ & & + & & \\
\hline 15 & Male (23) & ++ & & + & & \\
\hline 10 & Male (22) & + & ++ & & & + \\
\hline 1 & Male (21) & & ++ & & & \\
\hline 5 & Female (20) & & ++ & & & \\
\hline 11 & Female (1) & & ++ & & + & + \\
\hline 3 & Male (1) & + & ++ & & & + \\
\hline 6 & Male (trainee) & + & ++ & & + & + \\
\hline 16 & Female (24) & & ++ & & + & + \\
\hline 13 & Male (12) & & ++ & & + & + \\
\hline 7 & Female (14) & & ++ & & + & \\
\hline 8 & Male (1) & & ++ & & & \\
\hline 14 & Male (trainee) & & ++ & & & + \\
\hline 12 & Male (27) & & & ++ & + & \\
\hline 18 & Male (23) & & & ++ & & + \\
\hline 9 & Male (17) & + & & ++ & & \\
\hline 4 & Female (12) & & + & & ++ & + \\
\hline 17 & Female (4) & + & + & & & ++ \\
\hline 19 & Male (1) & & + & & + & ++ \\
\hline 20 & Female (trainee) & & + & & + & ++ \\
\hline
\end{tabular}


As an example, there's this group home for mentally disabled youth. Many have odd syndromes that a GP might not even have heard of, and may also receive neurological or endocrinology treatments. As the poor GP, I am just handed some papers and suddenly I am supposed to sign changes to the drug list, and I have no idea why they were made in the first place. I never really get any information about it either (GP No. 2).

Most GPs said their responsibility had increased with time, as limited hospital resources result in an increased number of patients with complicated conditions in the primary care.

The trend in health care is that more and more work is done in primary care. If I had done some of the things I do today some 20 years ago, I would have received a warning or been fired. A GPs' area of responsibility is so much bigger than it used to be. We are seeing patients who suffer from cancers, hematologic diseases, renal failure, and severe heart failure... Not only has the collective knowledge grown, we are also able to offer more pharmacological treatments and at the same time hospitals are receiving less patients as their resources shrink. As a result, I am prescribing drugs I am not qualified to prescribe (GP No. 15).

\section{Category B. Responsible for Own Prescriptions}

The GPs mainly felt responsible for their own prescriptions and how these drugs interact with the current patient drug list. Taking responsibility for all drugs prescribed to a patient was perceived as an impossible task in this view. The GPs cited lack of comprehensive information from other clinicians and from the National Corporation of Swedish Pharmacies (Apoteket). If the GP received information about medication the patient was currently taking, either from the patient or in a referral, the GP made sure potential drug-drug interactions or side effects would be avoided.

Since there is no database, it's difficult to place responsibility for all information on anyone. I can't assume responsibility for what other doctors prescribe, and with all the current integrity rules, I can't even get information about what drugs a patient is using from Apoteket. The way I see it, I simply can't assume responsibility for other prescriptions than the ones I am writing. However, I need to consider earlier medication, make sure they don't interact or turn out to be unsuitable together in any way (GP No. 6).

Some GPs said they would take responsibility only for drugs they prescribe to patients listed at their clinic. They were likely to feel more responsibility toward elderly patients who take many different medications, whereas young or middle-aged patients were viewed as competent to handle the responsibility themselves. Some also said the responsibility to inform the physician rests heavily with the patient, because time pressures prevent a detailed review by the GP.

The patient needs to make the request for an overhaul of the drugs himself or herself because it's impossible for us to track down where every patient has been before or discuss that with the patient. There isn't enough time. Age may be a factor to consider, though. People over 80 may not be able to deal with it themselves and may also be on lots of different medications, so in that case you would usually want to keep track of what they are taking. Patients who are about 40 years old and have an allergy will be expected to keep track on their own. Some responsibility is, in fact, placed on the patient. If a patient seeks care for an obviously common infection, I would expect them to know that they need to inform us if they also suffer from some immunological disorder or some other special condition, without my asking them (GP No. 11).

\section{Category C. Responsible for All Drugs}

The GPs felt responsible for all drugs prescribed to a patient. This view reflected an assumed responsibility for the patient's total well-being, which was different from the understanding in category $\mathrm{A}$, where the GPs more or less felt they had another prescriber's responsibility dumped on them. The common view was that the responsibility physicians must assume in every meeting with a patient automatically requires an assessment that takes into account all prescribed drugs.

In my view, the issue of taking responsibility is present every time a physician who prescribes drugs meets a patient. You are obliged to make an assessment based on all current drugs the patient is taking and what the near future will be like for that individual. When you think that period of time is up, or when all parties feel safe and comfortable with it, it's important to follow up on the treatment by seeing the patient again. Then the process starts again. In between appointments it may be difficult to demand responsibility because so much is going on, but the formal responsibility is there nonetheless. Basically the only thing you can do is to ask the patient to get in touch if he or she isn't feeling well (GP No. 18).

To create a feeling of safety for the patient as well as the GP, the physician used a defined strategy. Such a strategy included interviewing patients about what other drugs they were taking, following up closely on the treatment, and asking patients to return if they felt unwell after taking the medication. Some GPs said they should, as the family doctor, have the legal responsibility for all drugs prescribed to the patient.

It's an impossible task for, let us say, an eye specialist that my multi-drug-using patient is seeing to take responsibility for the blood-pressure medication I prescribed when that specialist only looks at the eye and prescribes eye drops. In practice the responsibility lies with the physician who sees the patient regularly, but legally it is the last doctor to write a prescription who is responsible (GP No.12). 
Category D. Different but Shared Responsibility GPs and patients had their respective areas of responsibility.

I am responsible for adding changes to the list and following up on them. At the same time I can't assume responsibility on a wider scale because it is an impossibility. In my view, patients are in charge of their treatment and the medications they are taking, because people may consult several specialists for different ailments and get prescriptions from several different places. As a GP, I couldn't possibly take an overall responsibility in those situations. It can't be done. The patient must assume a big responsibility (GP No. 19).

The GP had knowledge about drugs and felt responsible for safety, such as knowing about an appropriate indication for each drug and drug-drug interactions. The patient was responsible for taking the drugs according to the GPs instructions and for telling their physicians what other medication they may have been prescribed by other physicians. The GP sought to strengthen the patient's sense of understanding and personal responsibility for the treatment through discussions with the patient on why and how to use a particular drug. One GP pointed out that medical attendance has a paternalistic tradition, which made the patient passive, without responsibility, "the patient should do what the doctor says." GPs believed the only way to change this view was to get patients more involved in their own treatment.

It could be that we have sort of made drugs a part of the doctor's world. It's a health care product that the patient needs to take. It is like you need to get people to understand that this is actually your drug that you choose. I print out drug lists for my patients and tell them "this is what you are supposed to be taking according to my notes, and now go and check if you have these drugs at home, please." It is a way to get patients more involved, it is their personal medication. I believe in that. I think this is a very exciting subject, but it doesn't fit well with rational and fast health care (GP No. 4).

GPs said they also collected information by ordering copies of medical records from their patients' other physicians, a work described as time consuming.

\section{Category E. Patient Transferring Drug Information}

The patient was responsible for drug information transfer between physicians. This approach emphasized that the patient is the only one to have a complete picture of the drugs he or she is using, because patients often visit different prescribers. The GPs also talked about the patient integrity law as a threat to patient safety. This law does not allow physicians and the pharmacies to share information about the patients' prescribed drugs.
The patient receives the care and is then made the messenger, due to some integrity reason that prevents health care professionals from exchanging information. The problem is people don't remember. They are unable to recall what they were prescribed or if they actually got it, they have other things on their minds (GP No. 4).

As a result, patients were seen as having a huge responsibility for their own drug treatments and for informing physicians of what medications they use. GPs depend on this information while prescribing or in follow-up treatment.

The patient can see any doctor in the Stockholm area they like. There are lots of physicians with private clinics, and nobody lets me know when they've been to one of them. I am aware of my information being outdated, so I need to check with the patient, who doesn't always know either and may have forgotten the drug list at home. So sometimes you just have to tell them to bring all their pill jars with them next time (GP No. 16).

GPs said one reason patients do not tell what drugs they use could be that they believe physicians have access to that information through electronic medical records. When asked about their drugs, a major problem was that patients were not always regarded as reliable sources of information. GPs said patients often do not remember what kind of drug they are taking.

\section{Outcome Space}

Table 2 shows how understanding responsibility is distributed among the GPs interviewed, as expressed in the 5 categories of $\mathrm{A}$ through $\mathrm{E}$. How these categories relate to each other is displayed in the outcome space (Figure 1). The outcome space, which can be viewed

\section{Figure 1. Outcome space of internal relationship between 5 categories: the GPs' collective approach to managing responsibility for patient drug lists. \\ Category D. Different but shared responsibility between GP and patient

\begin{tabular}{|l|l|}
\hline $\begin{array}{l}\text { Category E. } \\
\text { The patient is } \\
\text { responsible for } \\
\text { drug informa- } \\
\text { tion transfer } \\
\text { between } \\
\text { prescribers }\end{array}$ & $\begin{array}{c}\text { Category C. GP is responsible for all pre- } \\
\text { scribed drugs }\end{array}$ \\
\cline { 2 - 2 } & $\begin{array}{c}\text { Category B. GP is mainly responsible for } \\
\text { own prescriptions and how these drugs } \\
\text { interact with the current patient drug list }\end{array}$ \\
\cline { 2 - 2 } & $\begin{array}{l}\text { Category A. GP feels an imposed respon- } \\
\text { sibility from previous prescriber }\end{array}$ \\
\hline
\end{tabular}

$\mathrm{GP}=$ general practitioner.

Note: Category $D$ is the most comprehensive; it comprises a broader understanding because it includes aspects of the other 4 categories ( $A, B, C$, and $E)$, as well as the patient perspective on drug therapy. In contrast, GPs expressed a more restricted understanding in category $A$, often excluding aspects from above categories. 
as a work map, represents the GPs' collective approach to what they focus on in managing responsibility for patient drug lists.

The 5 categories constitute a hierarchy of understanding responsibility. Category D is the most comprehensive, not only because it incorporates aspects of categories A, B, C, and E, but also because it includes the patients' perspective on drug therapy. In this category the GP adopts a patient-centered approach. ${ }^{18}$ Category D might even facilitate the patient's role as a distributor of information between physicians (described in category E), a responsibility the patients seem to have difficulty managing. ${ }^{19}$ Category E affected all categories because of the importance of having access to patientspecific drug information in prescribing.

In category $\mathrm{C}$, the GPs stated they have the overall responsibility for all drugs prescribed to a patient. The patients are the focus but are not seen as active participants. The GPs have a doctor-centered approach, and communication is more biomedically oriented. ${ }^{20}$ To transition from category $\mathrm{C}$ to $\mathrm{D}$ would mean that the GP would have to adopt a broader way of understanding responsibility to take into account the patient's perspective.

Most GPs' understanding of responsibility is described by category B, in which the GPs focused mainly on their own prescriptions. Table 2 shows that 11 GPs reported their predominant understanding to be in this category. These GPs described a culture of passivity and lack of initiative when not asking the patients about what drugs they take. Earlier research has shown that this passive attitude exists. ${ }^{19,21}$ We did not question why the GPs reported this passive understanding in our study.

Category A was interpreted as the most restricted way of understanding responsibility. GPs in this category engaged in a passive approach to prescription management when they renewed prescriptions or signed drug lists for diseases they did not feel competent to manage. From the perspective of these GPs, the patients' role is also described as passive.

\section{DISCUSSION}

This study shows that GPs vary in how they perceive responsibility for current patient drug lists. Variations occurred even though the GPs were aware of medical directives to be responsible for their own prescriptions, as well as for the current drugs on a patient's drug list, and even though they knew patients may need to take more responsibility for their own drug treatments than they were aware. Our findings correlate with those of recent European ${ }^{9,20}$ and North American ${ }^{22}$ studies that identified several areas where preventable drug-related problems could potentially arise. These areas included information gaps in patients' drug histories, communication problems between patients and health care professionals, and communications problems between health care professionals in patient care management. Because information exchange between care facilities was incomplete, the GPs were forced to make decisions based on limited patient-specific information about drug use $e^{9,22}$ The information gaps also put the burden of responsibility on the patient for passing along information between physicians (as described in category E). The situation is further complicated in that patients are often not able to tell what drugs they take and therefore fail to distribute the needed information. Earlier research has shown that patients frequently asked their GPs "what medications they were taking." ${ }^{19}$

It is important that patients understand what prescriptions they are taking as part of becoming responsible for their own well-being (described in category D). When the patients have several prescribers, the risk of errors increases, eg, possibility of duplication of drugs and potential drug-drug interactions. ${ }^{22}$ Patients who understand their drug treatment are more likely to ask questions about the usefulness of another drug that has a similar effect and or other drug-related concerns. When the patient asks questions, the GP's ability to correct misinformation increases, which makes prescribing decisions more judicious and informed. ${ }^{23}$ Ensuring that patients understand and become more active in safely managing their own prescriptions requires that GPs acquire adequate information ${ }^{9}$ and develop competence in involving patients in shared decision making. ${ }^{24}$ Shared decision making requires communication between GPs and patients, which is neither original nor difficult to practice. ${ }^{25}$ What is difficult is finding an appropriate way to educate GPs to improve clinical communication. ${ }^{25,26}$

How GPs understand responsibility for patients' drug lists varies according to the type of patient (age) and the problem (illness, disease). Because an understanding of their responsibility for patients' drug lists varied among this group of GPs, it will also likely vary among specialists. A related study of an emergency care unit showed that physicians did use the patientspecific drug list, but only as a tool to diagnose the patient's condition. Drug treatments were not normally changed because the physicians said they were unable to follow up on the treatment. ${ }^{27}$

The GPs believed that a joint database of all drugs prescribed to a patient will solve many problems related to the current patient drug lists. We must ask ourselves how likely this scenario is in reality. What will happen in the future when harmonization of laws and technical solutions make all prescribed drugs transparent to all 
prescribers? Will the technical solutions force the prescribers from different disciplines to think about responsibility in the same way? How should we construct these technical support systems, such as computer-assisted prescribing and shared patient medical records, so that they facilitate a consensus of understandings between different professionals and the patients?

This study indicates that along with development in health care technology, the question of how GPs understand their responsibility for the patient's drug list today might be a first step to understanding their future responsibility. Further studies of how GPs and other professionals think about this issue are required.

If we want to prevent drug errors, technical solutions alone are unlikely to be sufficient. ${ }^{9,28}$ In theory, technical solutions should make a substantial difference, but in practice it is also necessary to develop methods of human communication and improve practical reasoning. ${ }^{9,25,26}$ It is possible to develop practical reasoning and communication skills by reflecting on experiences. Using a phenomenographic method, we found views varied among GPs. Group discussions to reflect on descriptions of responsibility in relation to patient safety may help some GPs expand their views. This reflection process could be arranged as an educational intervention where the GPs reflect on the outcome space. ${ }^{15,16}$

To read or post commentaries in response to this article, see it online at http://www.annfammed.org/cgi/content/full/8/1/40.

Key words: Medications; drug history; family practice; qualitative research; phenomenography

Submitted September 24, 2008; submitted, revised, May 6, 2009; accepted May 18, 2009

Funding support: Grants were received from the Stockholm County Council and Karolinska Institutet, ALF Medicine (Dnr 20050849) and The Swedish Research Council (Dnr 522-2005-7461).

Acknowledgments: We are very grateful to the participating GPs for sharing their understandings in the interviews.

\section{References}

1. von Euler M, Eliasson E, Ohlén G, Bergman U. Adverse drug reactions causing hospitalization can be monitored from computerized medical records and thereby indicate the quality of drug utilization. Pharmacoepidemiol Drug Saf. 2006;15(3):179-184.

2. Patel P, Zed PJ. Drug-related visits to the emergency department: how big is the problem? Pharmacotherapy. 2002;22(7):915-923.

3. Bates DW, Spell N, Cullen DJ, et al.; Adverse Drug Events Prevention Study Group. The costs of adverse drug events in hospitalized patients. JAMA. 1997;277(4):307-311.

4. Kramer JS, Hopkins PJ, Rosendale JC, et al. Implementation of an electronic system for medication reconciliation. Am J Health Syst Pharm. 2007;64(4):404-422.

5. Saufl NM. Reconciliation of medications. J Perianesth Nurs. 2006; 21(2):126-127.
6. Jylhä V, Saranto K. Electronic documentation in medication reconciliation-a challenge for health care professionals. Appl Nurs Res. 2008;21(4):237-239.

7. Reinfeldt $F$, Hägglund G. Regeringens proposition 2007/08:126. http://www.sweden.gov.se/sb/d/9251/a/101487.

8. Wettermark B, Bergman U, Krakau I. Using aggregate data on dispensed drugs to evaluate the quality of prescribing in urban primary health care in Sweden. Public Health. 2006;120(5):451-461.

9. Howard R, Avery A, Bissell P. Causes of preventable drug-related hospital admissions: a qualitative study. Qual Saf Health Care. 2008;17(2):109-116.

10. Socialstyrelfsen. SOSFS. The National Board of Health and Welfare's regulations on drug prescribing in the Swedish health service. http://www.sos.se/sosfs/2000_1/2000_1.htm.

11. Marinker M, Shaw J. Not to be taken as directed. BMJ. 2003;326 (7385):348-349.

12. Marton F. Phenomenography-describing conceptions of the world around us. Instr Sci. 1981;10(2):177-200.

13. Marton F, Booth S. Learning and Awareness. Mahwah, NJ: Lawrence Erlbaum Associates; 1997.

14. Sandberg J. Understanding human competence at work: An interpretive approach. Acad Manage J. 2000;43(1):9-25.

15. Lindberg EB. Increased job satisfaction after small group reflection on an intensive care unit. Dimens Crit Care Nurs. 2007;26(4):163-167.

16. Marton F, Pang Ming F. Two faces of variation. In: 8 th European Conference in Learning and Instruction. http://www.ped.gu.se/biorn/ phgraph/civil/graphica/pwy.pdf. 1999.

17. Patton M. Qualitative Evaluation and Research Methods. 2nd ed. Newsbury Park, CA: Sage Publications; 1990.

18. Roter D. The enduring and evolving nature of the patient-physician relationship. Patient Educ Couns. 2000;39(1):5-15.

19. Sleath B, Roter D, Chewning B, Svarstad B. Asking questions about medication: analysis of physician-patient interactions and physician perceptions. Med Care. 1999;37(11):1169-1173.

20. van den Brink-Muinen A, Verhaak PFM, Bensing JM, et al. Communication in general practice: differences between European countries. Fam Pract. 2003;20(4):478-485.

21. Richard C, Lussier MT. Measuring patient and physician participation in exchanges on medications: Dialogue Ratio, Preponderance of Initiative, and Dialogical Roles. Patient Educ Couns. 2007:65(3):329-341.

22. Tamblyn R, Huang A, Perreault R, et al. The medical office of the 21st century (MOXXI): effectiveness of computerized decision-making support in reducing inappropriate prescribing in primary care. CMAJ. 2003;169(6):549-556.

23. Epstein RM, Shields CG, Franks P, Meldrum SC, Feldman M, Kravitz RL. Exploring and validating patient concerns: relation to prescribing for depression. Ann Fam Med. 2007;5(1):21-28.

24. Elwyn G, Edwards A, Kinnersley P, Grol R. Shared decision making and the concept of equipoise: the competences of involving patients in healthcare choices. Br J Gen Pract. 2000;50(460):892-899.

25. Frank A-W. Asking the right question about pain: narrative and phronesis. Lit Med. 2004;23(2):209-225.

26. Montgomery K. How Doctors Think. Clinical Judgement and the Practice of Medicine. Oxford: Oxford University Press; 2006.

27. Bastholm Rahmner P, Tomson G, Rosenqvist U, Gustafsson L, Holmström I. "Limit work to here and now" - A focus group study on how emergency physicians view their work in relation to patients' drug treatment. Intl I Qual Stud Health Well. 2008;3(3):155-164.

28. Chiang V. Commentary on electronic documentation in medication reconciliation - a challenge for health care professionals. Appl Nurs Res. 2008;21(4):240-241. 